\title{
ベイズ理論に基づく初期症状の情報価值に関する定量的評価手法の検討
}

\author{
大嶋 繁, ${ }^{a}$ 家田真祐子, $b$ 山本 碧, ${ }^{a}$ 小林大介 $*, a$
}

\section{Quantitative Evaluation Method of Information Value of Initial Symptoms Based on Bayesian Theory}

\author{
Shigeru Ohshima, ${ }^{a}$ Mayuko Ieda, ${ }^{b}$ Midori Yamamoto, ${ }^{a}$ and Daisuke Kobayashi ${ }^{*, a}$ \\ ${ }^{a}$ Department of Analytical Pharmaceutics and Informatics, Faculty of Pharmaceutical Sciences, \\ Josai University; 1-1 Keyakidai, Sakado, Saitama 350-0295, Japan; and ${ }^{b}$ Depaartment of \\ Pharmacy, Honjo General Hospital; 1780 Kitabori, Honjo, Saitama 367-0031, Japan.
}

(Received February 17, 2012; Accepted March 15, 2012)

\begin{abstract}
In accordance with Article 25-2 of the Pharmacists Act, pharmacists provide patients with information about the initial symptoms of adverse drug reactions for detecting and preventing those reactions. Thus far, however, there have been no reports quantitatively evaluating the usefulness of such information. We present a theory of information evaluation using posterior probability $(\mathrm{PP})$, positive likelihood ratio $(\mathrm{LR}(+))$ and incidence of nonspecific initial symptoms (NIS) - a measure of general symptoms without anything come to mind. First, we calculated using the data from the clinical trials. For liver damage caused by loxoprofen sodium hydrate, the $\mathrm{LR}(+)$ was as high as 27.9 in the presence of rash, but the PP was 0.002067 , which means there were only 2 liver damage cases among 1000 rash cases. Calculated in the same way for voriconazole, the LR $(+)$ was 5 and the PP was 0.2 ( 1 liver damage case among 5 rash cases). This suggests that information about rash as an initial symptom of liver damage is useful for patients taking voriconazole. However, the PP was greatly reduced when it was calculated by considering NIS. Since patients cannot distinguish initial symptom of side effect from mere change in body condition, the calculation considering NIS is realistic. Therefore, it is necessary to study in order to raise the value of the information service of the pharmacist. Our study demonstrates how PP and NIS, our new effective measure, allow a quantitative evaluation of the usefulness of information about initial symptoms.
\end{abstract}

Key words — adverse drug reaction; quantitative evaluation of information; initial symptom; posterior probability; likelihood ratio

\section{緒言}

副作用に関する 39 報の前向き研究をメタアナリ シスした米国のレビューでは，深刻な副作用の発現 率は $6.7 \%$ であり, 内訳は, 入院患者 $2.1 \%$, 外来 患者 $4.6 \%$ であった。 また，入院する原因の $4.7 \%$ は副作用であったと報告している。ささらに，副作用 は死亡原因の 4-6 位に位置すると示されている. ${ }^{1)}$ 日本においては，副作用に関して統合的にレビュー された報告はないが，米国と同様に，副作用による 患者不利益が生じていると推察される。また， Gandhi らは, 外来患者の 4 分の 1 は副作用を経験 しており，そのうちの 3 分の 1 ，すなわち 12 人に 1

The authors declare no conflict of interest. $a$ 城西大学薬学部薬剂作用解析学講座, ${ }^{b}$ 本庄総合病院 *e-mail: dkoba@josai.ac.jp
人は看過された副作用であったと報告している，彼 らは，考察において，副作用が見過ごされていた原 因は医師と患者のコミュニケーション不足であった

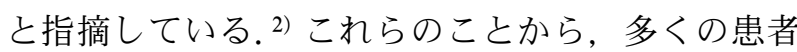
に副作用が生じ，その多数は副作用のモニタリング や情報提供により予防可能なものであり，患者の不 利益を減少させる方策として, 医療提供者側の適切 な情報提供が挙げられる.

わが国では，平成 9 年に施行された薬剤師法第二 十五条の 2 により，薬剤師は調剤した薬剤の適正な 使用のために必要な情報を提供することが義務とな り，とりわけ，副作用の重篤化を防止する 1 つの方 法として, 副作用の初期症状を情報提供してい る.3)しかし，提供する初期症状は患者にとって理 解し易い症状を選択するため, ありふれた体調の変 化が中心となり，医薬品に起因する症状であるかの 
判断が難しいことが多い。例えば，倦怠感や食欲不 振等の症状は医薬品を服用していなくても起こり得 る症状であり，患者によっては，重篤な副作用の初 期症状であることに気づかず，対処せずに重篤化を 招くことや，副作用でないにもかかわらず過敏に反 応し，常に副作用の発現を疑うことも考えられ る. 4,5) これらのことは, 初期症状を患者に情報提供 することが，無用な混乱を生じさせる可能性のある ことを意味している。 そのため，初期症状の情報と しての価值を定量的に評価し，その価值に基づいた 情報提供について検討されるべきであるが，現在ま でそのような検討はなされていない。そこで,

Bayes の定理に着目した. Bayes の定理による推定 では, 疾患に起因するなんらかの症状の発現や検査 結果の陽性率から，真に疾患である確率が計算でき る.

Ghajar らは，スルホンアミド服用中の皮疹の発 生がスルホンアミドに起因するのか否か, その診断 確率を上げるための方法を報告している. ${ }^{6}$ 皮疹の 特徵や発症時期, 服用の中止や再投与に対する反応 を鑑別診断の要因として用い, Bayes の定理を利用 して，診断確率を上げるための計算を行っている. 例えば，同じ皮疹であっても，スルホンアミドに起 因する皮疹の発症が服用初期に限られるのであれ ば，発症時期の情報は診断確率の上昇に寄与する. すなわち, Bayes の定理では, 疾患や副作用に関連 する事象単独あるいは事象の組み合わせによって, 真に疾患である, あるいは, 真に副作用である確率 の計算が可能となる.

この考え方は, 副作用の初期症状の情報提供を評 価するためにも利用できる.

そこで, 本研究では, Bayes 統計学で用いられて いる事前確率，事後確率及び尤度比の概念 ${ }^{7,8)}$ を, 副作用シグナルとしての初期症状の定量的評価に応 用することを試みた。

また, 初期症状として提供されている種々体調変 化の日常的な発生率（以下，非特異的初期症状発現 率）について，インターネットリサーチを利用して 調べた。これは, 初期症状として提供している体調 変化が, 医薬品の作用とは無関係に, 日常的に発生 し易いものである場合, 副作用シグナルとしての価 值は低いと考えられるためで，この確率の大小を利 用することによっても，情報価値を見積もることが
できるためである.

本研究においてわれわれは, 初期症状を発疹, 副 作用を肝障害として, 数種医薬品の事後確率及び尤 度比を試算した。

なお，本文中において，Bayes 統計学の用語であ る事後確率に, 直感的なわかり易さの観点から, 疫 学等で用いられる用語である的中率を併記すること とした.

\section{理論及び方法}

一般に, ある検査を行う前に, 検査の対象者が疾 病である確率は, 対象者を含む母集団中での疾病者 の割合を用いて表し，これを事前確率とする. 次 に，検査を実施し陽性と出た場合，真にその疾病に 罹患している確率を事後確率（的中率）とする，検 查は，事前確率に比べて高い事後確率を得ることを 目的として行われる。 すなわち，検査の有用性は， より高い事後確率（的中率）と，事前確率に対して どれだけ事後確率を高めたかにより評価でき，後者 は陽性尤度比 \{Positive Likelihood Ratio: LR $(+)$ \} （以下，尤度比）がその尺度になる。ここで, 事前 確率を医薬品の副作用発現率, 検査を副作用の初期 症状とおきかえると, 副作用シグナルとしての初期 症状の有用性も事後確率及び尤度比を用いることで 評価できる.

1. 事前確率と事後確率（的中率）医薬品 D の服用による副作用 $\mathrm{S}$ の発現と初期症状 I の発現の 関係を Fig. 1 に示す.

Figure 1 より，事前確率及び事後確率（的中率） は次のように与えられる.

事前確率 $=P_{\text {pre }}$

事後確率 (的中率 $)=$

$$
\begin{gathered}
\frac{P_{\text {pre }} Q_{\text {pre }}}{P_{\text {pre }} Q_{\text {pre }}+P_{\text {other }} Q_{\text {other }}+P_{\text {non }} Q_{\text {non }}} \\
\text { ただし, } P_{\text {pre }}+P_{\text {other }}+P_{\text {non }}=1
\end{gathered}
$$

2. 尤度比検査結果が陽性であった場合, 患 者が罹患している確率がどれくらい上昇するかの指 標として，尤度比が用いられており, ${ }^{8)}$ 疾病にかか っている人が陽性の結果となるオッズと正常な人が 陽性の結果となるオッズの比で示される.

$$
O d=\frac{P}{1-P}
$$




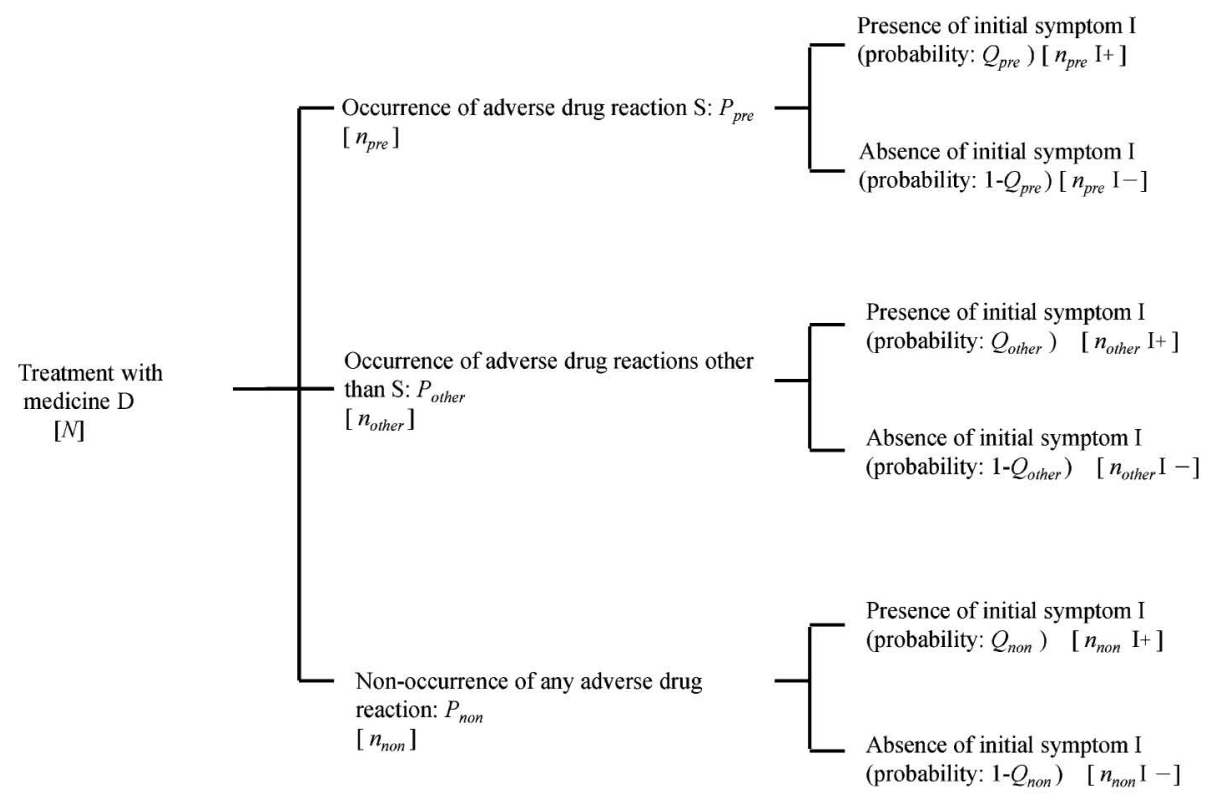

[ ] : number of subject in each blanch

Fig. 1. Probability Tree Diagram Expressing the Occurrence of Adverse Drug Reactions and the Presence of an Initial Symptom

$$
\begin{aligned}
& P=\frac{O d}{1+O d} \\
& L R(+)=\frac{O d_{\text {post }}}{O d_{\text {pre }}} \\
& =\frac{P_{\text {post }}\left(1-P_{\text {pre }}\right)}{P_{\text {pre }}\left(1-P_{\text {post }}\right)}
\end{aligned}
$$

ただし,$P=$ 確率, $P_{\text {pre }}=$ 事前確率, $P_{\text {post }}=$ 事後 確率, $O d=$ オッズ, $O d_{\text {pre }}=$ 事前オッズ, $O d_{p o s t}=$ 事後オッズ, $L R(+)=$ 陽性尤度比.

3. 計算に必要なデータの入手 医薬品インタ ビューフォーム（以下，IF）の「項目別副作用頻 度及び臨床検査值異常一覧」（以下，副作用一覧）, 及び, 独立行政法人医薬品医療機器総合機構（以 下，総合機構）の「副作用が疑われる症例報告」を 利用した.

\section{4. 事後確率の計算と前提}

4-1. 計算の前提 副作用一覧には,「悪心」, 「発疹」,「瘙痒」,「めまい」などの初期症状と同様 の症状（以下，副作用症候）が，独立した副作用と して記載され，発現症例数が示されている。この発 現症例数は 1 名が複数の副作用を発現した場合，そ れぞれの副作用に対して例数を 1 としてカウントさ れたものである.すなわち，副作用の種類別症例数 の合計は総症例数を上回る。 そのため，副作用症候
の発現症例数には，他の副作用の初期症状として発 現した症状（症例）も含まれていることを前提とし て計算した。

\section{4-2. 事後確率の計算}

$P_{\text {pre }}$ : 副作用一覧から, 肝障害の発現確率を求め た。ただし，承認時までの調査で肝障害が発現しな かつた医薬品については，使用成績調査も含めて計 算した。

$Q_{\text {pre }}$ :「副作用が疑われる症例報告」から, 医薬 品毎に，単独投与時の肝障害の症例を集め，これら の中で発疹を伴った症例の率を求めた。発疹及び類 似の症状は ICH 国際医療用語集日本語版（Med$\mathrm{DRA} / \mathrm{J}$ ）に収載されている基本語（Preferred Term: PT）レベルに統一して集計し，皮疹は発疹 としてまとめた.

Equation (2)の分母 $P_{\text {pre }} Q_{\text {pre }}+P_{\text {other }} Q_{\text {other }}+P_{n o n}$ $Q_{n o n}$ : 本式の計算結果は総症例における発疹の発現 率そのものであるため, 副作用一覧における発疹の 発現率 $Q_{t}$ として計算した. Figure 1 を用いると $Q_{t}$ は次のように表される.

$$
\begin{aligned}
Q_{t} & =\frac{\left(n_{\text {pre }} \mathrm{I}+\right)+\left(n_{\text {other }} \mathrm{I}+\right)+\left(n_{\text {non }} \mathrm{I}+\right)}{N} \\
& =P_{\text {pre }} Q_{\text {pre }}+P_{\text {other }} Q_{\text {other }}+P_{\text {non }} Q_{\text {non }}
\end{aligned}
$$

5. 調査対象医薬品の選択 医薬品添付文書の 
重大な副作用に肝障害の記載のある医薬品として, ボリコナゾール，フェノフィブラート，スルファメ トキサゾール/トリメトプリム合剤, チクロピジン 塩酸塩，イトラコナゾール及びロキソプロフェンナ トリウム水和物を選択して試算した。 IF はこれら の先発医薬品のものを利用した.

\section{6. 非特異的初期症状発現率の調査 重篤副作} 用疾患別対応マニュアル ${ }^{9)}$ から副作用の初期症状と して記載率の高い症状を 50 項目抽出し，これらに ついて，楽天リサーチ株式会社（東京）を通じてア ンケート調査を行った.

われわれは，これまで，同様のアンケート調査に よって, 副作用発症者と非発症者の体質の違いを調 べ，解析した経験を有する. ${ }^{10)}$

調査は, 2011 年 11 月 25 日から 2011 年 12 月 8 日にインターネットを利用して実施した。調査対象 者は楽天リサーチに登録されたモニターであり，20 歳代から 70 歳代までの 6 階級それぞれ男女別に 150 人ずつ, 合計 1800 人から回答を得た。アン ケートは，それぞれの症状（体調変化）について， 過去 3 力月の経験の有無を尋ねるもので, 回答は次 のような選択肢とした.

a. 薬の副作用としての体調変化（医師に診断さ れた薬の副作用による症状)

b. 薬の副作用ではない原因のある体調変化

例：病気の症状, 体質による症状, 加齢による症 状，更年期障害による症状，ゴルフなどの運動をし
て起きた筋肉痛や食べ過ぎによる胃もたれなど

c. 薬の副作用ではない原因不明の体調変化（薬 の副作用ではない症状で，思い当たる原因が一切な いのに起きた体調変化）

d. 体調変化なし

非特異的初期症状の発現率は, c. の選択肢を選 んだ回答者の率とした。

なお，われわれは，楽天リサーチより，回答者を 特定不可能な回答結果のみを受け取った。

\section{結 果·考 察}

\section{1. 初期症状提供の有用性評価 調査対象とし} た医薬品の計算結果を Table 1 に示す。また，非特 異的初期症状発現率の調査結果を Table 2 に示す.

最も事後確率 (的中率) の高い医薬品はボリコナ ゾールの 0.208330 であり, 事前確率の 0.05 を 4 倍 に上昇させた。発疹を初期症状として情報提供する ことで， 20 人に 1 人の肝障害発症者を 5 人に 1 人 まで絞り込むことができ，情報提供の有用性が示唆 された，尤度比はロキソプロフェンナトリウム水和 物が最も高く27.9であった。この点において，情 報としての価值は高いものの，元来，事前確率が極 めて低く, また, 事後確率も 0.002 と低く, 医薬品 服用後に発疹を発現しても，1000人に 2 人しか的 中しない。 そのため, 肝障害のシグナルとしての価 值には疑問が持たれる. 同様に, 他の医薬品の事後 確率（的中率）も，0.003571（イトラコナゾール）-

Table 1. Evaluation of the Usefulness of Rash for Detecting Liver Damage

\begin{tabular}{lcccccc}
\hline \hline \multicolumn{1}{c}{ Medicines } & $\begin{array}{c}\text { Prior } \\
\text { probability }\end{array}$ & $\begin{array}{c}\text { Posterior } \\
\text { probability }\end{array}$ & $\begin{array}{c}L R \\
(+)\end{array}$ & $\begin{array}{c}\text { Total cases } \\
\text { in clinical } \\
\text { studies }(N)\end{array}$ & $\begin{array}{c}\text { Total } \\
\text { rash } \\
\text { cases }(n)\end{array}$ & $Q_{\text {pre }}\left(\frac{1}{\text { hepatic damage cases }}\right)$ \\
\hline Voriconazole & 0.050000 & 0.208330 & 5.0 & 100 & 2 & $0.0833\left(\frac{1}{12}\right)$ \\
Fenofibrate* & 0.003414 & 0.035730 & 10.8 & 1256 & 10 & $0.0833\left(\frac{4}{48}\right)$ \\
Sulfamethoxazole/trimethoprim & 0.000907 & 0.019139 & 21.5 & 2204 & 38 & $0.3636\left(\frac{4}{11}\right)$ \\
Ticlopidine hydrochloride* & 0.001765 & 0.004472 & 2.5 & 1120 & 13 & $0.0294\left(\frac{2}{68}\right)$ \\
Itraconazole & 0.000806 & 0.003571 & 4.4 & 1240 & 8 & $0.0286\left(\frac{1}{35}\right)$ \\
Loxoprofen sodium hydrate* & 0.000074 & 0.002067 & 27.9 & 1700 & 13 & $0.2131\left(\frac{13}{61}\right)$ \\
\hline
\end{tabular}

\footnotetext{
* The incidence of adverse drug reactions was calculated using post-marketing data.
} 
Table 2. Incidence of Nonspecific Initial Symptoms

\begin{tabular}{|c|c|}
\hline Symptom & Incidence rate \\
\hline fatigue & 0.164 \\
\hline pruritus & 0.145 \\
\hline malaise & 0.134 \\
\hline headache & 0.125 \\
\hline diarrhea & 0.116 \\
\hline arthralgia & 0.114 \\
\hline tinnitus & 0.100 \\
\hline abdominal distension & 0.096 \\
\hline constipation & 0.088 \\
\hline somnolence & 0.087 \\
\hline dizziness & 0.086 \\
\hline rash & 0.083 \\
\hline insomnia & 0.080 \\
\hline pollakiuria & 0.078 \\
\hline sore throat & 0.078 \\
\hline abdominal pain & 0.076 \\
\hline abdominal discomfort & 0.070 \\
\hline palpitations & 0.061 \\
\hline muscle ache & 0.057 \\
\hline nasal mucosa or gum bleeding & 0.056 \\
\hline epigastrial pain & 0.056 \\
\hline thirst & 0.054 \\
\hline heart burn & 0.053 \\
\hline chest pain & 0.052 \\
\hline hypesthesia & 0.052 \\
\hline blood pressure increased & 0.049 \\
\hline dry cough & 0.049 \\
\hline edema & 0.044 \\
\hline nausea & 0.043 \\
\hline anemia & 0.042 \\
\hline hyperhidrosis & 0.041 \\
\hline muscle stiffness & 0.041 \\
\hline erythema & 0.039 \\
\hline wet cough & 0.039 \\
\hline decreased appetite & 0.038 \\
\hline pyrexia & 0.035 \\
\hline tachycardia & 0.029 \\
\hline face edema & 0.029 \\
\hline dyspnea & 0.025 \\
\hline bruise & 0.024 \\
\hline black stool & 0.023 \\
\hline lisp & 0.021 \\
\hline limb weakness & 0.020 \\
\hline oliguria & 0.019 \\
\hline vomiting & 0.019 \\
\hline tremor & 0.019 \\
\hline wheezing & 0.016 \\
\hline ageusia & 0.015 \\
\hline oral hypoesthesia & 0.008 \\
\hline bloody urine & 0.008 \\
\hline
\end{tabular}

Table 3. Calculation of Posterior Probability and Likelihood Ratio on Assumption that Rashes as Nonspecific Initial Symptoms Occured in All Subjects in Clinical Trials

\begin{tabular}{lcc}
\hline \hline \multicolumn{1}{c}{ Medicines } & $\begin{array}{c}\text { Posterior } \\
\text { probability }\end{array}$ & $\begin{array}{c}\text { Likelihood } \\
\text { ratio }\end{array}$ \\
\hline Voriconazole & 0.04045 & 0.80 \\
Fenofibrate & 0.00313 & 0.92 \\
Sulfamethoxazole/trimethoprim & 0.00329 & 3.64 \\
Ticlopidine hydrochloride & 0.00055 & 0.31 \\
Itraconazole & 0.00026 & 0.32 \\
Loxoprofen sodium hydrate & 0.00017 & 2.35 \\
\hline
\end{tabular}

0.035730（フェノフィブラート） と，低い值であつ た.

発疹の非特異的初期症状発現率の調査結果は 0.083 であった（Table 2)。この值は，調査対象と した医薬品の臨床試験における発疹の発現率（Table 1 の $n / N$ で示される值；肝障害とは限らない) よりも高いものであった．臨床試験での副作用は, 医薬品と因果関係があるものの夕選択されているた め, 非特異的に発生する症状はカウントされていな い. しかし，日常の臨床では，医薬品を服用してい る患者が非特異的に発生するこれらの症状と副作用 の初期症状とを識別することはできない.そこで, 医薬品を服用した患者が非特異的初期症状の発現も 含めて，副作用のシグナルとしてとらえる場合の事 後確率 (的中率) を試算した結果を Table 3 に示す. 計算は, 非特異的初期症状はすべての被検者に対し て，副作用と因果関係のある症状とは別に，同じ確 率で発生することを仮定して，便宜的に Eq. (2)の 分母を「 $Q_{t}+$ 非特異的初期症状発現率」として行つ た.

その結果, すべての医薬品の事後確率 (的中率) は大きく低下し，ボリコナゾールの尤度比は 1 を下 回った。これらのことから，仮に，患者が発疹の情 報提供に正しく対応し，副作用の可能性を排除せず に医療機関を受診すると，実際に副作用であるケー スの 25 倍（ボリコナゾール）-5000 倍（ロキソプロ フェンナトリウム水和物）に受診患者がふくれあが る計算になる，そのため，情報提供を効果的で効率 的にするための方法が考案されるべきである.

複数の情報が相互に影響しないとき，これらの情 報の同時提供による尤度比は個々の尤度比のかけ算 になる. 副作用の発症時期や発疹のタイプなどの副 
作用の特徵をあわせて情報提供することが有用とな る可能性があり, 今後の課題である.

2. 非特異的初期症状発現率 非特異的初期症 状発現率はその值が小さいほど有用である. 事後確 率の分母を小さくし，的中率を上昇させるためであ る，疲れ易い，皮膚のかゆみ，体がだるい，頭痛， 下痢，関節の痛み，耳鳴りはその確率が 0.1 を超え， 10 人に 1 人は，原因が明らかでないのに， 3 カ月に 1 度は経験する体調の変化である。 そのため, これ らのような確率の高い体調変化のみを情報として提 供した場合には，患者自身が副作用に気づくことは 難しい，一方，味覚異常や口唇のしびれは，副作用 シグナルとしての情報価值の高いことが示唆された.

今後，これらの確率を利用して，肝障害に対する 発疹の情報提供の有用性評価と同様の検討を行い, 効果的で効率的な情報提供の方法論を構築すること が望まれる。

\section{3. 研究の限界}

(1) 非特異的初期症状発現率の調査期間は 3 力月 であり，臨床試験の期間とかならずしも一致しな い。しかし，肝障害及び発疹の副作用は，通常，3 カ月以内に発生するものと思われる. ${ }^{11)}$ そのため, 結果に及ぼす期間の影響は少ないと思われる.

(2) フェノフィブラート，チクロピジン塩酸塩及 びロキソプロフェンナトリウムでは，市販後調査の 結果から $P_{\text {pre }}$ を算出しているため, $P_{\text {pre }}$ を過小評価 している可能性がある.

（3）IF の副作用一覧には，副作用（有害事象で はない）が記載されていることから，「医薬品との 因果関係がある有害な作用」として扱つた。しか し，重大な副作用のような重症度の高い副作用に伴 う発疹の初期症状は見逃されているか，あるいは， 記載漏れのある可能性は否定できない.

(4) $Q_{p r e}$ は，総合機構の「副作用が疑われる症例 報告」を利用し，発疹の記載のある症例報告の率か ら求めたが, 症例によっては, 発疹の症状が記載漏 れしている可能性は否定できない.

（5）「副作用が疑われる症例報告」には，重篤な 症例が多いと推察され，一方，臨床試験あるいは使 用成績調査では，軽微な症例から重篤な症例まで含
まれることから， $P_{p r e}$ の母集団と $Q_{\text {pre }}$ の母集団とが 一致していない可能性がある.

本研究には以上のような限界が想定される. しか し，本研究は初期症状の情報提供を定量的に評価し た初めての研究であり, Bayes 理論を利用する評価 の手法に重みを置いている. また, 日常的な体調変 化である非特異的初期症状発現率を調査して示し， これを利用した情報提供の定量的評価にも言及し た。そのため, 初期症状情報提供の定量的価值につ いておおよその目安を与えたものと考えている.

\section{REFERENCES}

1) Lazarou J., Pomeranz B. H., Corey P. N., JAMA, 279, 1200-1205 (1998).

2) Gandhi T. K., Weingart S. N., Borus J., Seger A. C., Peterson J., Burdick E., Seger D. L., Shu K., Federico F., Leape L. L., Bates D. W., N. Engl. J. Med., 348, 1556-1564 (2003).

3) Tsuchiya F., Yakkyoku., 49, 1976-1982 (1998).

4) Fries J. F., Loftus E. F., CA Cancer J. Clin., 29, 316-318 (1979).

5) Myers M. G., Cairns J. A., Singer J., Clin. Pharmacol. Ther., 42, 250-253 (1987).

6) Ghajar B. M., Lanctot K. L., Shear N. H., Naranjo C. A., Semin Dermatol., 8, 213-218 (1989).

7) Lanctôt K. L., Naranjo C. A., Clin. Pharmacol. Ther., 58, 692-698 (1995).

8) Grimes D. A., Schulz K. F., Lancet, 365, 1500 -1505 (2005).

9) Ministry of Health, Labour and Welfare: 〈http://www.info.pmda.go.jp/juutoku/juutoku index.html $\rangle$, Pharmaceuticals and Medical Devices Agency Web, cited 10 September, 2011.

10) Ohshima S., Hatori Y., Honma S., Terasawa K., Saitoh Y., Kobayashi D., Yakugaku Zasshi, 131, 745-756 (2011).

11) Ministry of Health, Labour and Welfare: 〈http://www.info.pmda.go.jp/juutoku/file/ jfm0804002.pdf $\rangle$, Pharmaceuticals and Medical Devices Agency Web, cited 10 September, 2011. 